\title{
Değer Merkezli Okul Kültürü Ölçeğinin Geliştirilmesi: Geçerlilik ve Güvenirlik Çalışması*
}

Development of Values-Centered School Culture scale:

A Study of Validity and Reliability*

Mahmut ZENGİN, Sorumlu Yazar. Doç. Dr.

Sakarya Üniversitesi, İlahiyat Fakültesi, İlköğretim DKAB Eğitimi Bölümü.

E-mail: zengin@sakarya.edu.tr

ORCID: 0000-0002-9042-7379

Muhammet Enes ÇELİK, Yüksek Lisans Öğrencisi.

Sakarya Üniversitesi, Eğitim Bilimleri Enstitüsü.

E-mail: enescelik5419@gmail.com

ORGID: 0000-0001-8269-8681

ISSN: 1303-880X

e-ISSN: 2667-7504

http://ded.dem.org.tr

Geliş/Received: 18.03.2019

Kabul/Accepted: 08.05.2019

Makale türü/Article type:

Araştırma/Research
Atıf/Citation: Zengin, M. \& Çelik, M.E. (2019). Değer merkezli okul kültürü ölçeğinin geliştirilmesi: Geçerlilik ve güvenirlik çalışmas1. Değerler Eğitimi Dergisi, 17 (37), 317-348. DOI: $10.34234 /$ ded.541321

* Bu çalışma "Değer Merkezli Okul Kültürü Ölçeğinin Geliştirilmesi” konulu Yüksek Lisans tezi esas alınarak hazırlanmışır.

* This article is derived from a master thesis of "Development of values-centered school culture scale" 
Öz: Bu çalışmanın amacı, değer merkezli okul kültürünü ölçebilecek geçerlik ve güvenirlik çalışmaları yapılmış bir ölçek geliştirmektir. Araştırmanın çalışma grubunu Sakarya ilinde farklı eğitim kademeleri, okul türü ve branşlarda görev yapan 548 öğretmen oluşturmaktadır. Beşli Likert tipinde hazırlanan ve uzman görüşleri de alınan 54 maddelik taslak form öncelikle 247 öğretmenden oluşan ilk gruba uygulanmış ve elde edilen veriler açımlayıcı faktör analizinde kullanılmıştır. AFA sonuçlarına göre ölçek 35 madde ve 6 alt boyuttan oluşmaktadır. Bu alt boyutlar, değerlere dayalı vizyon ve stratejik planlama, okul-çevre ilişkisi, okul yönetimi-öğretmen işbirliği, öğretmen modelliği, mesleki gelişim, değerlerin öğretimini izleme ve değerlendirme olarak adlandırılmıştır. Daha sonra 35 maddelik ölçek doğrulayıcı faktör analizi için 301 öğretmenden oluşan ikinci bir gruba uygulanmıştır. DFA sonucunda ölçeğin yapısını bozan iki madde daha çıkarılmış ve 33 maddelik bir ölçeğe ulaşılmıştır. DFA sonuçları, ölçeğin model uyum indekslerinin iyi düzeyde olduğunu ve faktör yapısının doğrulandığını ortaya koymuştur. Elde edilen ölçeğin bütününe ve alt boyutlarına ilişkin Cronbach Alfa güvenirliği sırasıly .964; .946; .915; .924; .807; .915 ve .842 olarak bulunmuştur. Bu veriler, ölçeğin iç tutarlığının oldukça yüksek olduğunu göstermiştir. Bu kapsamda değer merkezli okul kültürünü belirlemek amacıyla geliştirilen 33 madde ve 6 boyuttan oluşan ölçeğin geçerli ve güvenilir bir ölçme aracı olduğu sonucuna varılmıştır.

Anahtar Kelimeler: Okul kültürü, Okul iklimi, Değerler eğitimi, Ölçek geliştirme, Değer merkezli okul

$\&$

Abstract: The aim of this study is to develop a scale with examined validity and reliability, that measures values-centered school culture. The study group consists of 548 teachers working in different education levels, school types and branches in Sakarya province. A 54-item draft form, which was prepared in the format of five-point Likert type, was applied on 247 teachers as a first group and the data obtained were used in Exploratory Factor Analysis. According to EFA results, the scale consists of 35 items and 6 sub-dimensions. These sub-dimensions are: values-based vision and strategic planning, school-environment relations, school management-teacher collaboration, teacher modeling, professional development, monitoring and evaluation of values. Then, 35-item scale was applied to a second group of 301 teachers for Confirmatory Factor Analysis. According to the CFA results, two item that affected the structure of the scale were removed, so a 33-item scale was reached. The CFA results showed that the 
model fit indexes of the scale were good and the factor structure was confirmed. The Cronbach's alpha reliability for the total and sub-dimensions of the scale was found $.964 ; .946 ; .915 ; .924 ; .807$, respectively. These data show that the internal consistency of the scale is quite high. In this context, it was concluded that the scale consisting of 33 items and 6 dimensions developed to determine values-centered school culture is a valid and reliable measurement tool.

Keywords: School culture, School atmosphere, Values education, Scale development, Values-centered school

\section{Giriş}

İnsanın varlık alanına özgü bir kavram olarak onun düşünce ve eylemlerine etki eden ve onları belirleyen ilkeler, davranışları yönlendiren genel kılavuzlar şeklinde tanımlanan değer/ler (Uysal, 2008; Halstead, 2005; Demircioğlu ve Tokdemir, 2008), eğitim, siyaset, iş dünyası, medya gibi hayatın birçok alanında sıklıkla üzerinde durulan bir konudur. Dünyada yaşanan hızlı değişim ve dönüşümler neticesinde ortaya çıkan yeni şartlar, değerlerin okullarda öğretilmesine yönelik bir bakış açısını gündeme getirmiştir. Bilimin değerler konusunda tarafsız olması anlayışına dayalı pozitivist bilim anlayışının etkisiyle okullar, değerlerin öğretiminde gerekli ve yeterli bir insiyatif alamamıştır. Bununla birlikte eğitimin mahiyeti itibariyle değer yüklü bir aktivite olduğu düşünüldüğünde okulların değerlerin öğretimi konusunda bazı sorumlulukları üstlenmesinin önemli kazanımlar sağlayacağı eğitim çevrelerinde dile getirilmeye başlanmıştır. Öğretmen, öğrenci, veli, okul yönetimi ve toplumdaki diğer tüm paydaşların ortak bir sorumluluğu olarak ele alınması gereken değerlerin öğretimi konusunda, okulların değer merkezli bir kültür oluşturması kritik bir öneme sahiptir (Zengin, 2017).

Okul kültürünün yapılandırılmasında paylaşılan değerlerin belirlenmiş olmas1 son derece kritiktir. Çünkü okul kültürü, öğrenciler, veliler, öğretmenler ve okul yöneticileri arasındaki ilişkilerin temelini oluşturur ve okul topluluğunun değerlerini, inançlarını ve gelişimlerini yansıtır. Bu bağlamda okul kültürü, her okulda bireylerin davranışlarını ve sosyal ilişkilerini düzenleyen ve yön veren sosyal bir olgudur (Peterson ve Deal, 1990). Bu yönüyle her okul, kendine özgü bir kültür, davranış ve ilişkileri şekillendiren ahlaki kod, söylem ve yaşam tarzını bünyesinde barındırmaktadır (Peterson ve Deal, 2002). 


\section{Değer Merkezli Okul Kültürü}

Okul kültürü ile ilgili tanımlamalara bakıldığında değerlerle ilişkisine yönelik bir boyutun mutlaka dikkate alındığg görülmektedir. Okul kültürü, okuldaki yöneticiler, öğretmenler ve diğer ilgili tüm paydaşların oluşturup geliştirdikleri, okuldaki davranış biçimlerini, normları ve değerleri belirleyen ve kişiler arasındaki ilişkileri düzenleyen bir yapıdır. Okul kültürü okul içinde ve dışında yer alan tüm çevrenin okulu algılama biçimini belirler ve okulun yaşam tarzını yansıtır (Göldağ, 2015: 78). Okul kültürünün oluşmasında okulun yaşı ve tarihi, amaç ve hedefleri, öğrencilerin sosyo-ekonomik düzeyleri, okulun bulunduğu sosyo-ekonomik ve coğrafi çevre, okulun sahip olduğu fiziki ve teknolojik imkanlar, yönetici, öğretmen ve öğrencilerin beklentileri, velilerin beklentileri, eğitim sisteminin yapısı gibi birçok faktör etkili olmaktadır (Özdemir, 2006: 414-415). Bir kültürü oluşturan unsurların hepsi ayrı bir öneme sahip olmakla birlikte bu unsurların en önemli olanının değerler olduğu konusunda ortak bir anlayış olduğu söylenebilir (Şahin Fırat, 2010).

Okulların öğrencilerin akademik başarılarını arttırma işlevleri yanında değerlerin kazandırılmasında daha başarılı olabilmeleri için değer merkezli bir okul kültürü inşa edebilecekleri planlama, ortak perspektif, birlikte çalışma, karar alma süreçlerine katılım, açık iletişim, ortak dil, zaman ve mekan düzenlemeleri, mesleki gelişim, işbirliği, destek ve güven, çevre ile ilişkiler, bütünleşme ve aidiyet gibi birçok süreci tanımlamış ve bunları hayata geçirmiş olmaları gerekir. Bu çalışmada okullarda değerlerin açık veya örtük bir şekilde kazandırılması süreçlerinde yöneticilerden öğretmenlere, okul çevresini oluşturan kişi veya kurumlardan öğrencilere kadar tüm paydaşların sorumlulukları olduğu düşüncesinden hareketle değer merkezli okul kültürü tanımlaması kullanılmış ve bununla değerlerin merkezi konumuna vurgu yapılması ve okul kültürünün oluşturulmasına etki eden tüm boyutların değerlerle ilişkisinin kurulması amaçlanmıştır. Okullarda değerlerin istenilen düzeyde kazandırılabilmesi açısından değer merkezli okul kültürünün birçok boyutundan bahsetmek mümkün olmakla birlikte bu çalışmada ölçek geliştirme sürecinin teorik çerçevesine de 1 şı tutan şu boyutların dikkate alınmasının önemli olduğu düşünülmektedir.

\section{Değerlere dayah vizyon ve stratë̈k planlama:}

Vizyon, gelecekte ulaşılmak istenen hedefleri ortaya koyan uzun soluklu bir süreç olarak tanımlanmaktadır (Özden, 2005). Günümüzde öğrencilerin akademik başarılarını arttırmaya yönelik okulların hedef ve uygulamalarının çok belir- 
gin olduğu bilinmektedir. Bununla birlikte okullar değerlerin öğretimi konusuna akademik başarı kadar yeterli ilgiyi göstermemekte ve bütünlük arz eden bir çalışma ortaya koyamamaktadırlar. Bu nedenle okul eğitimi ile ilişkili tüm paydaşlar tarafından paylaşılan değer odaklı bir vizyon ve planlamaya ihtiyaç bulunmaktadır. Değer merkezli bir okul kültürü oluşturabilmek için tüm okul topluluğu içerisinde okula rehberlik edecek değerler hakkında anlaşmaya varmak kritik öneme sahiptir. Okulun bu konudaki vizyonu, ders içi uygulamalar, planlama süreçleri, okulun öncelikleri, davranışsal beklentiler, yönetim anlayışı gibi birçok konuya dayanak oluşturur. Okullarda paylaşılan bir vizyon yoksa, tüm paydaşlar tarafindan sahiplenilmiyor ve paylaşılmıyorsa etkili, planlı ve sistematik bir değerler eğitimini gerçekleştirmek oldukça zordur. Bu kapsamda öncelikle okulun eğitim ile ilgili tüm planlamalarında değerler eğitimi açık bir hedef olmalı ve değerlerin kazandırılması konusunda okul yönetimi, öğretmenler, veliler ve diğer tüm paydaşlar ortak bir anlayışı yansıtmalıdırlar (Zengin, 2017; Curriculum Corporation, 2008, 25).

\section{Bütünleșik Program:}

Değerler eğitiminin, ayrı bir program veya öğretim programlarına ilave ayrı bir uygulama olarak değil, bir bütün olarak tüm öğretim programlarının konusu olarak görülmesi gerekir. Bu bağlamda değerler eğitiminin sadece belirli bir branş alanının parçası olarak görülmesi ve diğer alanların bu konuda yeterince inisiyatif almaması değerlerin kazandırılması süreçlerinden başarı elde etmeyi güçleştirir. Bu nedenle değerler eğitimi tüm öğretim programlarının tamamlayıc1 ve bütünleşik bir bileşeni olarak görülmelidir (Curriculum Corporation, 2008). Bu kapsamda değerlerin tüm branşlar düzeyinde öğretim programlarının amaç ve kazanımlarına entegre edilmesi yanında okul yaşamı içindeki tüm etkinlik ve uygulamalarda yer alması önemlidir. Okul yönetiminin ve tüm öğretmenlerin bu anlayış doğrultusunda ortak bir anlayışa sahip olması gerekmektedir (Kaymakcan ve Meydan, 2016).

\section{Model Olma:}

Bireylerin açık veya örtük bir şekilde söyledikleri ve yaptıklarının başkaları tarafından düşünce, tutum ve davranış olarak sergilenmesine etki etme olarak tanımlanabilecek model olma süreci, başarılı değerler eğitimi uygulamalarının ayrılmaz bir bileşeni olarak değerlendirilmektedir. Model olma, sadece öğretmenlerin açık veya örtük bir şekilde değerleri temsil etmesini değil, okuldaki herkesin tüm ilişkilerde bu temel ilkeyi dikkate almasını kapsar. Bu bağlamda 
öğretmenler öğrencilere model olabildiği gibi öğretmenler öğretmenlere, öğrenciler öğrencilere model olabilirler. Değerlerle ilgili böyle bir model olma süreci, değer merkezli okul kültürünün gelişmesine önemli katkılar sunar. Öğretmenlerin model olma sürecinde kritik fonksiyonları bulunmaktadır. Model olma, öğretmenin yaptığı her şeyde kendini gösterir ve okul yaşamının tüm diğer bileşenleriyle ilişkilidir. Öğrenciler, öğretilen içerikten daha çok, söylem ve davranışlardan daha fazla etkilenmekte ve öğrenmektedirler. Öğretmen modelliği, öğrencilerin değerler hakkındaki bilgilerine güçlü bir destek sağlar. Daha da önemlisi, değerlere dayalı tutum geliştirme, değerlerle ilgili hüküm verme ve sosyal beceriler geliştirmede anahtar bir bileşendir (Curriculum Corporation, 2008, 38-40). Öğretmenin değerler konusunda model olması yanında aile başta olmak üzere diğer paydaşlarla işbirliği yapılması ve değerlerin kazandırılması sürecine aktif katılımlarının sağlanması da kritik öneme sahiptir (Kaymakcan ve Meydan, 2016).

\section{Personelin Mesleki Gelişimi:}

Okulda görevli bulunan idari personel ile eğitim kadrosuna yönelik değerler eğitimi konusunda öğrenme imkânlarının oluşturulması ve bunun sürdürülebilir bir şekilde gerçekleştirilmesi gereklidir. Kaymakcan ve Meydan'ın da (2016) da işaret ettiği gibi, personelin değerler eğitimi konusunda gelişimlerinin sağlanmasında farkındalık oluşturularak teşvik edilmeleri, değerler eğitimi süreç ve uygulamaları noktasında bilgi ve becerilerinin geliştirilmesi, ayrıca gerekli eğitim materyalleri ile desteklenmeleri önemlidir. Okullarda uygulanan değerler eğitimi çalışmalarına yönelik yapılan çeşitli izleme ve değerlendirme çalışmalarından elde edilen verilerde özellikle öğrencilerle doğrudan etkileşim içinde bulunan öğretmenlere yönelik değerler eğitimi kapsamında sunulan mesleki öğrenme imkânlarının onların var olan uygulamalarını pozitif anlamda dönüştürdüğünü ortaya koymuştur (Curriculum Corporation, 2008, 44).

\section{Okul Paydaşlan ile Işsirliğgi:}

Değer merkezli okul kültürünün oluşumunda sadece okulda bulunan çalışanların sorumluluğu yoktur. Aynı zamanda öğretilecek değerlerden uygulama süreçlerine kadar tüm boyutlarda okul personelini, aileyi, yerel ve sivil toplum unsurları gibi çevre imkanlarını sürece dahil etmek ve işbirliklerini geliştirmek gerekmektedir. Her ne kadar değerler eğitimi ile ilgili bir girişimde birçok insanı sürece dâhil etmek çok zaman ve emek gerektirse de daha sağlam bir uzlaşma- 
y1, tutarlılığ1 ve sürdürülebilirliği sağlar (Curriculum Corporation, 2006). Okul değerlerin öğretimi konusunda iki temel zorlukla karşılaşabilir. Halstead'e göre (2005) bunlardan birisi, herkes için geçerli değerlerin belirlenmesi sürecidir. Farklı dünya görüşleri, dini ve sosyo-kültürel farkl1l1klar, kişi veya kurumların değerlerle ilgili önceliklerinin kimi zaman birbiriyle örtüşmemesi ve benzeri sebeplerle toplumda herkesin kabul edeceği değerleri belirleme ve bu değerlerin kazandırılması süreçleri konusunda uzlaşmanın zorlukları bulunmaktadır. Bir diğer zorluk ise okulda değerlerin öğretilmesinden elde edilen kazanımların okul dışında aile, medya, akran grupları gibi unsurlar tarafından desteklenmesinin sağlanabilmesinde yaşanmaktadır. Okulun değerlerin öğretilmesi ve temsil edilmesi noktasında gösterdiği hassasiyetin okul dışındaki paydaşlar tarafından da yeterince dikkate alınması ve işbirliği yapılması gerekmektedir. Okulun, paydaşlarla işbirliğini geliştirecek süreçleri tanımlaması ve uygulamaya yönelik perspektifinin olması önemlidir.

\section{Okula ve Topluma Görelik:}

Farklı ülkelerde aynı amaca odaklanmış ancak farklı kavramlar kullanılarak değerlerin okul sistemi içinde öğretildiği bilinmektedir. Amerika'da karakter eğitimi, Avrupa ülkelerinde vatandaşlık eğitimi, Avustralya'da değerler eğitimi bu bağlamda örnek olarak verilebilir. Farklı ülkelerdeki değerlerin öğretimine odaklanan bu programların hazırlanması ve uygulanması süreçlerinde ortak bazı noktalar bulunmakla birlikte ait oldukları toplumun ve okulların şartları, ihtiyaçları ve önceliklerinin dikkate alındığı görülmektedir. Aksi durumda değerlerin şekillendirdiği bir okul kültürü oluşturmak güçleşecektir. Değerlerin kazandırılmasında bulunduğu toplum ve okulu dikkate almak, o toplumun bu konudaki ihtiyaçlarını, toplumun tarihi ve kültürel değerlerini, değerlerin anlaşılma biçimini ve değerlerin oluşturduğu davranış standartlarını, bireyler arasındaki ilişkilerde değerlerin yansımalarını dikkate almak anlamına gelmektedir.

Okul kültürü bağlamında literatürde farklı ölçme araçları geliştirildiği görülmektedir. Öğretmenlerin okul kültürü hakkındaki düşüncelerini belirlemek üzere Gruenert ve Valentine (1998) tarafindan geliştirilen 35 maddelik okul kültürü ölçeğinde öğretmen işbirliği, işbirliğine dayalı liderlik, mesleki gelişme, ortak amaçlar, meslektaş desteği ve birlikte öğrenme boyutları bulunmaktadır. Değerlerin öğretimi ve değer merkezli okul kültürünün oluşmasında öğretmenlerin ve okulların kritik fonksiyonları bulunmaktadır. Bu bağlamda, Milson ve Ekşi (2003) tarafindan Amerika ve Türkiye'deki öğretmenlerden elde edilen veriler- 
le geliştirilen ve Türkçeye uyarlaması da yapılan bir diğer ölçek çalışmasında öğretmenlerin karakter eğitimi yetkinliği üzerinde durulmuştur. Acat ve Aslan (2011) ise, okullardaki çalışmaların karakter eğitimi felsefesine göre değerlendirilmesi amacıyla 33 madde ve 5 boyuttan oluşan "Okulların Karakter Eğitimi Yetkinlik Ölçeğị”ni geliştirmişlerdir.

Okul kültürünü ölçmeye yönelik diğer bazı çalışmalar bağlamında ilköğretim okullarındaki kültürel yapının belirlenmesi amacıyla Terzi (2005) tarafindan geliştirilen okul kültürü ölçeği; ayrıca Fırat (2007) tarafından, öğretmenlerin, görev yaptığı okulun kültürüne ilişkin görüşlerini saptamak amacıyla geliştirdiği Okul Kültürü Ölçeği; 36 madde ve 13 boyuttan oluşan ve öğretmenlerin okul kültürüne yönelik görüşlerini belirlemek amaciyla Şimşek (2005) tarafından geliştirilen ölçek çalışması; ilköğretim öğretmenlerinin algıları 1şı̆̆ında okul yöneticilerinin değerlere dayalı yönetim uygulamalarının okul kültürü üzerindeki etkisini incelemek amaciyla Demirtaş ve Ekmekyapar'ın (2012) geliştirdikleri ölçek; Maryland güvenli ve destekleyici okul iklimi ölçeği'nin Türk kültürüne uyarlanmasına yönelik Ekşi, Türk ve Avcu (2017) çalışması, Hemşirelik eğitimi veren kurumlarda öğrencilerin bakış açısından örgüt kültürünü belirlemeye yönelik Kantek, Baykal ve Altundaş'in (2010) geliştirdikleri ölçek; ilkokul öğretmen ve yöneticilerinin okul kültürüne ilişkin algılarını tespit etmek amacıyla Şahin (2010) tarafından geliştirilen Okul Kültürü Envanteri ayrıca zikredilebilir.

Tarafımızdan geliştirilen değer merkezli okul kültürü ölçeğinin tüm boyutları dikkate alındığında literatürde yer alan ve yukarıda belirtilen çalışmaların okulların değerler eğitimini planlama ve geliştirme süreçleri, öğretmenlerin kritik fonksiyonları gibi ortak bazı boyutları bulunmakla birlikte bu çalışmamızda okul kültürüne etki eden boyutların değerlerle ilişkisinin daha belirgin ve kapsayıcı bir şekilde ele alındığı düşünülmektedir. Bu nedenle ölçekte okul kültürünün her bir boyutunda değerlerin etkisi ve fonksiyonunu ön plana çıaran maddelere yer verilmiş, okul kültürü ve değerler ilişkisinin belirgin bir şekilde kurulması amaçlanmıştır. Okulların oluşturmaya çalıştıkları veya oluşturdukları okul kültüründe değerlerin ne düzeyde dikkate alındığını değerlendirmede bu ölçek ile elde edilecek geribildirimlerin önemli olduğu değerlendirilmektedir.

Konu ile ilgili yapılan alan yazın incelemesinde Türkiye'de değer merkezli okul kültürünü ölçmeye yönelik ölçme aracı geliştirmenin önemli bir katkı sağlayacağı göz önünde bulundurularak değer merkezli okul kültürünün belirlenebilmesi için bir ölçme aracının geliştirilmesi düşünülmüştür. Bu araştırmada değerlere daya- 
11 bir okul kültürünün hangi temel boyutları yansıtması gerektiğinden hareketle değer merkezli okul kültürü ölçeğinin geliştirilmesi amaçlanmıştır. Ölçeğin uygulanmasından elde edilecek verilerin, değerlerin öğretimi ve değer merkezli bir okul kültürü oluşturma bağlamında ilgili tüm paydaşlara (veli, öğretmen, öğrenci, STK, okul personeli vb.) katk1 sağlayacağı düşünülmektedir.

\section{Araştırmanın Yöntemi}

Değer merkezli okul kültürü ölçeğinin geliştirilmesinde nicel araştırma desenlerinden geçmiş veya içinde bulunulan dönemde varlığını devam ettiren durumları olduğu gibi yansıtmayı amaçlayan betimsel tarama modeli kullanılmıştır (Karasar, 2016).

\section{Çalışma Grubu}

Değer Merkezli Okul Kültürü Ölçeğinin geliştirilmesi sürecinde açımlayıcı faktör analizi (AFA) için 247 ve doğrulayıcı faktör analizi (DFA) çalışmaları için 301 olmak üzere Sakarya'da çalışan toplam 548 öğretmen çalışmaya dâhil edilmiştir. AFA ve DFA için iki farklı çalışma grubu üzerinde çalışılmıştır.

AFA ve DFA analizlerinin gerçekleştirildiği çalışma gruplarının cinsiyet, çalıştıkları okul kademesi, branş, öğrenim düzeyi, mesleki kıdem ve çalıştıkları okul türlerine ilişkin bilgiler Tablo 1'de yer almaktadır.

Tablo 1: Çalışma Grubunun Özellikleri

\begin{tabular}{|c|c|c|c|c|c|}
\hline & & \multicolumn{2}{|c|}{ İlk Çalışma Grubu } & \multicolumn{2}{|c|}{ İkinci Çalışma Grubu } \\
\hline & & $f$ & $\%$ & $f$ & $\%$ \\
\hline \multirow{3}{*}{ Cinsiyet } & Kadın & 145 & 58,7 & 145 & 48,2 \\
\hline & Erkek & 102 & 41,3 & 156 & 51,8 \\
\hline & Toplam & 247 & 100,0 & 301 & 100,0 \\
\hline \multirow{9}{*}{ Okul Kademesi } & İlkokul & 52 & 21,1 & 18 & 6,0 \\
\hline & Ortaokul & 92 & 37,2 & 70 & 23,3 \\
\hline & İmam Hatip Ortaokulu & 39 & 15,8 & 41 & 13,6 \\
\hline & Anadolu Lisesi & 21 & 8,5 & 46 & 15,3 \\
\hline & İmam Hatip Lisesi & 2 & 0,8 & 38 & 12,6 \\
\hline & Mesleki ve Teknik A. Lisesi & 41 & 16,6 & 36 & 12,0 \\
\hline & Fen Lisesi & 0 & 0 & 33 & 11,0 \\
\hline & Temel Lise & 0 & 0 & 19 & 6,3 \\
\hline & Toplam & 247 & 100,0 & 301 & 100,0 \\
\hline
\end{tabular}




\begin{tabular}{|c|c|c|c|c|c|}
\hline \multirow{5}{*}{ Eğitim Durumu } & Ön Lisans & 6 & 2,4 & 1 & 0,3 \\
\hline & Lisans & 203 & 82,2 & 241 & 80,1 \\
\hline & Lisansüstü & 38 & 15,4 & 54 & 17,9 \\
\hline & Cevap Vermeyen & 0 & 0 & 5 & 1,7 \\
\hline & Toplam & 247 & 100,0 & 301 & 100,0 \\
\hline \multirow{8}{*}{ Mesleki Kıdem } & $1-5 \mathrm{y} 11$ & 63 & 25,5 & 75 & 24,9 \\
\hline & 6-10 y1l & 57 & 23,1 & 44 & 14,6 \\
\hline & $11-15 \mathrm{y} 11$ & 52 & 21,1 & 53 & 17,6 \\
\hline & $16-20$ y1l & 43 & 17,4 & 49 & 16,3 \\
\hline & $21-25 \mathrm{y} 11$ & 25 & 10,1 & 34 & 11,3 \\
\hline & $26+y 11$ & 7 & 2,8 & 39 & 13,0 \\
\hline & Cevap Vermeyen & 0 & 0 & 7 & 2,3 \\
\hline & Toplam & 247 & 100,0 & 301 & 100,0 \\
\hline \multirow{3}{*}{ Okul Türü } & Devlet Okulu & 247 & 100,0 & 221 & 73,4 \\
\hline & Özel Okul & 0 & 0 & 80 & 24,6 \\
\hline & Toplam & 247 & 100,0 & 301 & 100,0 \\
\hline \multirow{6}{*}{ Branş } & $\begin{array}{l}\text { Türkçe-Sosyal Alanlar } \\
\text { (Türkçe, Sosyal Bilgiler, Tarih, Felsefe, } \\
\text { Edebiyat, Coğrafya, Tarih, İngilizce, } \\
\text { DKAB, Müzik, Beden vb.) }\end{array}$ & 140 & 56,7 & 165 & 54,8 \\
\hline & $\begin{array}{l}\text { Fen-Matematik Alanları } \\
\text { (Matematik, Fen Bilgisi, Fizik, Kimya, } \\
\text { Biyoloji vb.) }\end{array}$ & 49 & 19,8 & 80 & 26,6 \\
\hline & $\begin{array}{l}\text { Mesleki-Teknik Lise Alanları } \\
\text { (Elektrik, Makina, Metal, Moda } \\
\text { Tasarım, Mobilya, Yiyecek-İcecek, } \\
\text { Pazarlama vb.) }\end{array}$ & 12 & 4,9 & 30 & 10,0 \\
\hline & Sınıf Öğretmenliği & 46 & 18,6 & 13 & 4,3 \\
\hline & Cevap vermeyen & 0 & 0 & 13 & 4,3 \\
\hline & Toplam & 247 & 100,0 & 301 & 100,0 \\
\hline
\end{tabular}

Açımlayıcı faktör analizi için araştırmaya katılan öğretmenlerin \%58,7'si $(n=145)$ kadın, \%41,3'ü ( $n=102)$ ise erkeklerden oluşmaktadır. Aynı zamanda \%21,1 ( $\mathrm{n}=52)$ İlkokul, \%37,2 (n=92) Ortaokul, \%15,8 ( $\mathrm{n}=39)$ İmam Hatip Ortaokulu, 8,5 ( $\mathrm{n}=21)$ Anadolu Lisesi, 0,2 ( $\mathrm{n}=2)$ İmam Hatip Lisesi, 16,6 $(\mathrm{n}=41)$ oranında ise Mesleki-Teknik Anadolu Lisesi öğretmenlerinden oluşmaktadır. Eğitim durumlarına baktığımızda \%2,4 $(\mathrm{n}=6)$ ön lisans, \%82,2 (n=203) Lisans, \%15,4'ü $(n=38)$ ise lisansüstü mezunudur. Öğretmenlerin Mesleki K1dem durumlarına baktığımızda \%25,5'i (n=63) 1-5 yıl, \%23,1'i (n=57) 6-10 y1l, \%21,1'i (n=52) 11-15 yı1, \%17,4'ü (n=43) 16-20 y1l, \%10,1'i (n=25) 2125 y1l, \%2,8'i (n=7) 26 ve üstü olarak görülmektedir. İlk uygulamaya katılan öğretmenlerin tamamı devlet okulunda çalışmaktadır. Öğretmenlerin içerisinde bulunduğu branş alanlarına baktığımızda \%56,7'si (n=140) Türkçe-sosyal alanlar, \%19,8'i (n=49) fen-matematik alanları, \%4,9'u (n=12) mesleki-teknik lise alanları, \%18,6’sı (n=46) ise sınıf öğretmenliği alanı olduğu görülmektedir. 
DFA uygulaması için araştırmaya katılan öğretmenlerin \%48,2'si (n=145) kadın, \%51,8'i ( $\mathrm{n}=156)$ ise erkeklerden oluşmaktadır. Aynı zamanda öğretmenlerin çalıştıkları okul kademesi \%6,0 ( $\mathrm{n}=18)$ İlkokul, \%23,3 ( $\mathrm{n}=70)$ Ortaokul, \%13,6 (n=41) İmam Hatip Ortaokulu, \%15,3 (n=46) Anadolu Lisesi, \%12,6 $(\mathrm{n}=38)$ İmam Hatip Lisesi, \%12,0 ( $\mathrm{n}=36)$ Mesleki-Teknik Anadolu Lisesi, $\% 11,0(\mathrm{n}=33)$ Fen Lisesi, \%6,3 ( $\mathrm{n}=19)$ oranında ise Temel Liseden oluşmaktadır. Eğitim durumlarına baktı̆̆ımızda \%0,3 $(\mathrm{n}=1)$ ön lisans, \%80,1 $(\mathrm{n}=241)$ Lisans, \%17,9’ü ( $\mathrm{n}=54)$ ise lisansüstü mezunudur. Öğretmenlerin \%1,7'si (n=5) eğitim düzeyi seçeneğine cevap vermemiştir. Öğretmenlerin Mesleki Kıdem durumlarına baktığımızda \%24,9'u (n=75) 1-5 yıl, \%14,6's1 (n=44) 6-10 yı1, \%17,6's1 (n=53) 11-15 y1l, \%16,3'ü (n=49) 16-20 yı1, \%11,3'ü (n=34) 21-25 yıl, \%13,0’1 (n=39) 26 ve üstü olarak görülmektedir. Öğretmenlerin \%2,3’ü $(\mathrm{n}=7)$ Mesleki Kıdem seçeneğini işaretlememiştir. Öğretmenlerin çalıştıkları okul türlerine baktığımızda 73,4'ü (n=221) devlet okulu, \%24,6’sı $(\mathrm{n}=80)$ ise resmi okul olduğu görülmektedir. Öğretmenlerin içerisinde bulunduğu branş alanlarına baktığımızda \%54,8'si (n=165) Türkçe-sosyal alanlar, \%26,6'sı $(\mathrm{n}=80)$ fen-matematik alanları, \%10,0'1 $(\mathrm{n}=30)$ mesleki-teknik lise alanları, $\% 4,3 ’ u ̈ u(n=13)$ ise sınıf öğretmenliği alanı olduğu görülmektedir.

\section{Veri Toplama Aracı}

"Değer Merkezli Okul Kültürü Ölçeğì"nin geliştirilmesi sürecinde öncelikle alan yazın taranmış, elde edilen bilgiler doğrultusunda ölçek için 57 maddeden oluşan bir madde havuzu oluşturulmuştur. Maddelerin yazılması sürecinde değer merkezli okul kültürünün oluşturulmasında önemli olduğunu düşündüğümüz okulun değerlere dayalı bir vizyon ve stratejik planlamaya sahip olması, okul-çevre ilişkisi, öğretmen modelliği, değerler eğitimini izleme ve değerlendirme, değerlerin öğretim programlarına entegre bir anlayışla öğretilmesi, okul yönetiminin değerler eğitimi konusunda öğretmenlerle işbirliği, personelin değerlerin kazandırılması süreçlerindeki mesleki gelişimi boyutları dikkate alınmıştır. Hazırlanan maddeler, kapsam geçerliliği için öncelikle değerler eğitimi konusunda uzman dört farklı akademisyene, ayrıca bir dil uzmanına incelettirilmiş, gelen geri dönütler doğrultusunda maddelerde düzenlemeler yapılmıştır. Ayrıca uygulamaya geçmeden önce hazırlanan ölçek maddelerinin anlaşılabilirliğini test etmek amacıyla sesli düşünme tekniği yoluyla dört öğretmenden maddeleri sesli bir şekilde okumaları ve cevaplamaları istenmiş, araştırmacı bu işlem esnasında öğretmenlerin anlamakta zorluk çektikleri veya tereddüt yaşa- 
dıkları maddeleri tespit etmiştir. Öğretmenlerin anlamakta zorluk yaşadıkları üç madde ölçekten çıkarılmış ve uygulama öncesi 54 maddelik bir deneme formu elde edilmiştir. Taslak formdaki her bir madde, "Kesinlikle Katılmıyorum (1), Katılmıorum (2), Kararsızım (3), Katılıyorum (4), Kesinlikle Kat1liyorum (5)" şeklinde beşli likert tipi dereceleme ölçeği doğrultusunda puanlanmıştır. Oluşturulan taslak form, Sakarya ilinde farklı okul türü, branş ve eğitim kademelerinde görev yapan 247 öğretmene uygulanmıştır. Açımlayıcı faktör analizine yönelik işlemler sonrasında elde edilen 35 madde ve 6 boyuttan oluşan ölçek doğrulayıcı faktör analizi için farklı 301 öğretmene daha uygulanmış ve analizleri yapılmıştır. DFA sonrası ulaşılan 33 maddelik ölçekten alınabilecek en yüksek puan 165, en düşük puan ise 33'tür. Ölçekten yüksek puan alınması, okulların değer merkezli okul kültürünü yansıtma düzeylerinin yüksek olduğu anlamina gelmektedir.

\section{Verilerin Analizi}

Kapsam geçerliğine ilişkin yapılan çalışmadan sonra ölçeğin yapı geçerliğini test etmek üzere açımlayıcı ve doğrulayıcı faktör analizi; güvenirliği test etmek için de Cronbach's Alpha iç tutarlık katsayısı hesaplanmıştır. Elde edilen veriler için kayıp veri analizi yapılmış, kayıp verilerin yerine seri ortalamaları alınarak analizlerinin yapılması kararlaştırılmıştır.

Değer merkezli okul kültürü ölçeğinin madde analizlerine yönelik işlemler, korelasyona dayalı analizle incelenmiş ve madde-ölçek korelasyonları Pearson korelasyon katsayısı ile değerlendirilmiştir. Analiz sonucunda ölçek puanıyla 0,30 altında korelasyon bulunan maddeler taslak formdan çıkarılmıştır (Tavşanc11, 2006; Büyüköztürk, 2016)).

Madde analizinin ardından AFA öncesinde verilerin faktör analizine uygunluğu için Bartlett küresellik testi ve Kaiser-Meyer-Olkin (KMO) sonuçları dikkate alınmıştır (Kalayc1, 2005; Tavşancıl, 2006; Büyüköztürk, 2016). AFA sonucunda ortaya çıkan faktör yapısının verilerle ne derece uyum gösterdiğini belirlemek amacıyla farklı bir gruptan elde edilen veri üzerinden doğrulayıc1 faktör analizi gerçekleştirilmiştir. Tüm analizler sonrasında ulaşılan ölçeğin ve ölçek boyutlarının güvenirliği, Cronbach Alfa güvenirlik katsayısı üzerinden değerlendirilmiştir. Geçerlik ve güvenirlik analizleri için SPSS 22 ve AMOS 21 programları kullanılmıştır. 


\section{Bulgular}

\section{Madde Analizine İlişkin Bulgular}

Değer merkezli okul kültürü ölçeği kapsamında hazırlanan 54 maddelik taslak form 247 öğretmene uygulanmıştır. Maddelerin ayırt ediciliğini ve toplam puanı yordama gücünü belirlemek amacıyla düzeltilmiş madde toplam korelasyonları hesaplanmış, madde toplam korelasyonlarının değerlendirilmesinde ise .30 ve daha yüksek olan maddelerin ölçülecek özelliği ayırt etme açısından yeterli kabul edildiği (Büyüköztürk, 2016: 181) göz önüne alınarak bu değerin altında kalan 30, 37, 39 ve 43. maddeler ölçekten çıkarılmıştır. Kalan 50 maddenin düzeltilmiş madde toplam korelasyonları .340 ile .752 arasında değer almış, Cronbach Alfa güvenirlik katsayısı ise .970 olarak bulunmuştur.

\section{Açımlayıcı Faktör Analizine İlişkin Bulgular}

50 maddeden oluşan ölçeğin faktör analizine uygunluğu için Kaiser-Meyer Olkin (KMO) ve Barlett Küresellik testi yapılmıştır. KMO değerinin .60'dan büyük ve Bartlett küresellik testinin anlamlı çıkması verilerin faktör analizine uygun olduğunu göstermektedir (Büyüköztürk, 2016: 136). Analiz sonucunda KMO değeri .94 olarak hesaplanmış, Barlett Küresellik testi $(\chi 2=9841,43$; $p<.001)$ anlamlı bulunmuştur. Bu sonuçlar doğrultusunda veri setinin faktör analizine uygun olduğu görülmüştür.

Değer Merkezli Okul Kültürü Ölçeği'nin yapı geçerliliğinin sınanması amacıyla açımlayıcı faktör analizi gerçekleştirilmiştir. Açımlayıcı faktör analizinde maddelerin ölçekten atılıp atılmamasına karar vermede faktör yük değerinin alt sınırı .40 olarak kabul edilmiştir. Ayrıca bir maddenin farklı faktörlerdeki yük değeri arasında en az.10 fark olması referans alınmış, bu kapsamda birden fazla faktörde binişiklik gösteren maddeler ölçekten çıkarılmışıtır. Literatürde bir maddenin faktör yük değerinin asgari 30 ve üzerinde olması yönünde yaygın bir kabul olmakla birlikte (Büyüköztürk, 2016; Tabachnick ve Fidell, 2001), bunun .40 olması gerektiğini belirtenler de bulunmaktadır (Şencan, 2005).

Tablo' 2'de "Değer Merkezli Okul Kültürü Ölçeği”nin açımlayıcı faktör analizinden elde edilen faktör yapısı, faktörlere ilişkin özdeğerler, açıklanan varyanslar ve maddelerin döndürülmüş faktör yük değerleri yer almaktadır. Tablo 2'de döndürülmüş maddelerin daha net görülebilmesi için analizde .30 altında kalan faktör yük değerlerine yer verilmemiştir. 
Tablo 2: Maddelerin Ortak Faktör Varyansı, Ölçeğin Faktör Yapısı, Madde Faktör Yükleri, Faktörlerin Öz Değerleri, Faktörlerin Açıkladığı Varyanslar ve Açıklanan Toplam Varyans

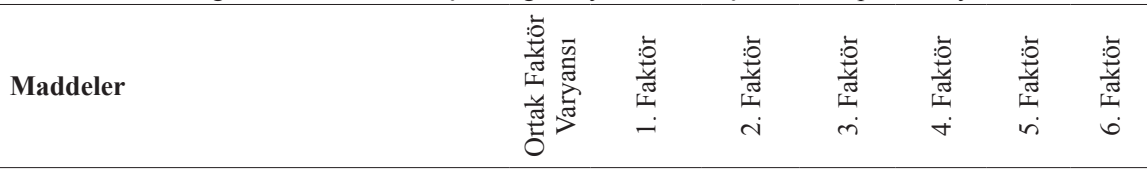

52. Okulumuzda değerlerin öğretilmesi, öğrencilerin okul eşyalarına ve rutin görevlere karşı sorumluluklarını geliştirmektedir.

51. Değerlerin öğretilmesi, okulumuzdaki disiplin sorunlarının azalmasına katkı .74 , 81 sağlamaktadır.

54. Okulumuzda değerlerin öğretimi, öğretmen ve öğrenciler arasında güvene dayalı ilişkileri arttırmaktadır.

$.80 \quad, 79$

50. Okulumuzda değerlerin öğretilmesi sayesinde öğrencilerin okul ve sınıf çalışmalarına katılım isteği artmaktadır.

$.76 \quad, 77$

48. Değerlerin öğretilmesi, okulumuzda ögrencilerin akademik başarılarına olumlu $\quad .71 \quad$,76 etki etmektedir.

49. Okulumuzda değerlerin öğretilmesi, öğrencilerin okula olan aidiyetlerini ve devam durumlarını pozitif yönde etkilemektedir.

53. Okulumuzda değerler eğitimine yönelik çalışmalar, okul-veli ilişkilerine $\quad \begin{array}{llll}74 & \mathbf{7 0} & \text {,35 }\end{array}$ olumlu etki etmektedir.

17. Veliler, okulumuzda yürütülen değerler eğitimi çalışmalarını bilmektedirler.

.70

, 79

12. Okulumuz, değerler eğitimi konusunda velileri bilgilendirmek için düzenli toplantilar yapar.

16. Okulumuz velilerin değerler eğitimi süreçlerine aktif katılımlarını sağlamaktadır.

15. Okulumuzda, paydaşların (veli, öğretmen, öğrenci, STK, okul personeli vb.) değerler eğitimine katkı sağlayabileceği uygulamalar $75 \quad, 75$ tanımlanmiştır.

13. Okulumuz, değerlerin öğretimi konusunda velilerin beklentilerini dikkate almaktadır. , 72

14. Veliler, okulumuzdaki değerler eğitimi çalışmalarını desteklemektedir.

, 69

18. Okul paydaşları (veli, öğretmen, öğrenci, STK, okul personeli vb.), öğrencilere kazandırılması gereken temel ahlaki değerler üzerinde uzlaşmıştır. 
3. Okulumuzda, değerlerin öğretimi konusunda farkındalık vardır.

6. Okulda hangi değerlerin öğretileceği konusunda tüm paydaşların (veli, öğretmen, öğrenci, STK, okul personeli vb.) ortak bir anlayışı bulunmaktadır.

2. Okulumuzda tüm paydaşlar (veli, öğretmen, öğrenci, STK, okul personeli vb.) tarafından önemsenen değerlere dayalı ortak bir vizyon bulunmaktadır.

\section{Okulumuzun değerler eğitimi}

konusundaki bakış açısı toplumun temel değerlerini yansıtmaktadır.

\author{
.71
}

, 74

5. Okulumuzda değerlerin öğretimine yönelik stratejik bir planlama bulunmaktadir.

7. Okulda öğretilecek değerlerin belirlenmesinde tüm paydaşların (veli, öğretmen, öğrenci, STK, okul personeli vb.) görüşleri alınmaktadır.

\section{5. Öğrencilerin değerlere uygun} davranışlarını teşvik eder, onları cesaretlendiririm.

$\begin{array}{ll}.69 & , 32 \quad, 73 \\ .68 & , 73\end{array}$

.71
$\mathbf{7 3}$

$\begin{array}{r}73 \\ \hline 73\end{array}$

\begin{tabular}{|c|c|c|c|c|c|c|}
\hline $\begin{array}{l}\text { 38. Öğrencilere değerlerin öğretimi } \\
\text { konusunda kendimi yeterli buluyorum. }\end{array}$ & .64 & & &, 71 & & \\
\hline $\begin{array}{l}\text { 31. Öğrencilere değerler konusunda iyi bir } \\
\text { rol model olduğumu düşünüyorum. }\end{array}$ & .65 & & & ,69 &, 34 & \\
\hline $\begin{array}{l}\text { 33. Derslerimde değerleri açık bir şekilde } \\
\text { öğretirim. }\end{array}$ & .68 &, 32 & &, 68 & & \\
\hline $\begin{array}{l}\text { 36. Öğrencilerin okul dışında da temel } \\
\text { değerlere uygun hareket etmeleri için } \\
\text { onları takip ederim. }\end{array}$ & .61 & & &, 56 & & ,44 \\
\hline $\begin{array}{l}\text { 34. Değerlerin öğretiminde velilerden } \\
\text { daha fazla sorumluluğum olduğunu } \\
\text { düşünüyorum. }\end{array}$ & .31 & & &, 48 & & \\
\hline $\begin{array}{l}\text { 19. Okul yöneticileri, öğretmenlerin } \\
\text { fikirlerine başvururlar. }\end{array}$ & .71 & & & &, 74 & \\
\hline $\begin{array}{l}\text { 20. Okul yönetimi, değerler eğitimi } \\
\text { çalışmalarını önemsemektedir. }\end{array}$ & .79 & ,32 & & &, 68 & \\
\hline $\begin{array}{l}\text { 22. Okul yönetimi ve öğretmenler } \\
\text { değerlere dayalı okul kültürüne önem } \\
\text { vermektedirler. }\end{array}$ & .77 & & &, 41 &, 66 & \\
\hline $\begin{array}{l}\text { 21. Okul yöneticileri, değerlerin öğretimi } \\
\text { konusunda liderlik yapar. }\end{array}$ & .60 & &, 37 & & ,63 & \\
\hline $\begin{array}{l}\text { 24. Okul yöneticileri ile öğretmenler } \\
\text { değerlerin öğretimi konusunda uzlaşı } \\
\text { içindedir. }\end{array}$ & .67 &, 35 & & & ,62 & \\
\hline $\begin{array}{l}\text { 42. Değerler eğitimi için çeşitli } \\
\text { kaynaklardan yararlanıyorum. }\end{array}$ & .71 & & & & & ,74 \\
\hline $\begin{array}{l}\text { 40. Değerler eğitimi konusunda yapılan } \\
\text { mesleki gelişim eğitimlerine katılmaya } \\
\text { çalışırım. }\end{array}$ & .61 & & & & & ,70 \\
\hline
\end{tabular}




\begin{tabular}{|c|c|c|c|c|c|c|c|}
\hline $\begin{array}{l}\text { 41. Meslektaşlarım, değerlerin öğgretimini } \\
\text { daha iyi yapabilmek için çeşitli eğitimler } \\
\text { ve materyallerle kendilerini sürekli } \\
\text { geliştirmektedirler. }\end{array}$ & .61 & & ,32 & & & &, 64 \\
\hline Faktörün Öz Değeri & & 14,70 & 3,20 & 2,23 & 1,82 & 1,34 & 1,02 \\
\hline Faktörün Açılkladığı Toplam Varyans & & $\% 15,70$ & $\% 14,79$ & $\% 13,17$ & $\% 10,18$ & $\% 9,44$ & $\% 6,25$ \\
\hline Açıklanan Toplam Varyans & & $\% 69,56$ & & & & & \\
\hline
\end{tabular}

Yapılan ilk faktör analizi sonrasında 50 maddelik ölçek formunda yer alan bazı maddelerin birden fazla faktörde yük gösterdiği, bazı maddelerin ise içerik olarak ilişkili olmayan faktörlere dağıldığı belirlenmiştir. Bu kapsamda 8, 9, 11, 25, 26 ve 32 numaralı maddeler binişik olmaları; 10, 23, 27, 28, 29, 44, 45, 46 ve 47 numaralı maddeler ise bulundukları faktör boyutuyla içerik olarak bütünlük oluşturmaması nedeniyle ölçekten çıkarılmıştır. Tablo 2'de görüldüğü üzere bu maddeler çıkarıldıktan sonra analiz tekrarlanmış ve öz değeri 1'den büyük 35 madde ve 6 alt boyuttan oluşan bir yapıya ulaşılmıştır. Bu alt boyutlar sırasıyla değerler eğitimini izleme ve değerlendirme, okul-çevre işbirliği, değerlere dayalı vizyon-stratejik planlama, öğretmen modelliği, okul yönetimi-öğretmen işbirliği ve personelin mesleki gelişimi olarak isimlendirilmiştir. 35 maddelik ölçeğin Cronbach Alfa güvenirlik katsayısı ise .957 olarak bulunmuştur.

Tablo 2'de görüldüğü üzere “Değer Merkezli Okul Kültürü Ölçeği’”nin, ilk boyutu olan "değerler eğitimini izleme ve değerlendirme" boyutunda 7 madde yer almakta, maddelerin faktör yük değerleri 0.70-0.83 arasında değişmektedir. $\mathrm{Bu}$ faktörün tek başına açıkladığı varyans \% 15.70'tir. "Okul-çevre işbirliği" olarak isimlendirilen ikinci boyutta 7 madde bulunmakta ve maddelerin faktör yük değerleri 0.57-0.79 arasında değişmektedir. İkinci boyutun tek başına açıkladığı varyans ise \% 14,79 olarak belirlenmiştir. Ölçeğin üçüncü boyutu olan "değerlere dayall vizyon-stratejik planlama" boyutunda 7 madde bulunmakta, maddelerin faktör yükleri 0.61-0.74 arasında değişmektedir. Bu faktörün tek başına açıkladığı varyans \% 13,17'dir. "Öğretmen modelliği” olan dördüncü boyut 6 maddeden oluşmakta, maddelerin faktör yükleri 0.48-0.73 arasında yer almaktadır. bu faktörün açıkladığı varyans \% 10,18'dir. Beşinci boyut olan "okul yönetimi-öğretmen işbirliği" boyutunda 5 madde yer almakta ve faktör yük değerleri 0.62-0.74 arasında değişmektedir. Bu boyutun açıkladığı varyans $\%$ 9,44'tür. "Personelin mesleki gelişimi”" olarak belirlenen altıncı boyutta ise 3 madde yer almakta ve bu maddelerin faktör yük değerleri 0.64-0.74 arasında değişmektedir. Bu faktörün açıkladığı varyans ise \% 6,25’tir. "Değer Merkezli Okul Kültürü Ölçeği”nin altı faktörünün birlikte açıkladığı toplam varyans \% 69,56'dır. 
Ölçeğin iç tutarlılığını analiz etmek amacıyla faktörler arasındaki korelasyonlara da bakılmıştır. Korelasyon analizine ait bulgular Tablo 3'te sunulmaktadır:

Tablo-3: Faktörler Arası Korelasyon

\begin{tabular}{|c|c|c|c|c|c|c|c|c|}
\hline & $\mathbf{X}$ & SS & 1 & 2 & 3 & 4 & 5 & 6 \\
\hline $\begin{array}{l}\text { 1. Faktör } \\
\text { (Değerler eğitimini izleme ve } \\
\text { değerlendirme) }\end{array}$ & 3,90 & ,73 & 1 & & & & & \\
\hline $\begin{array}{l}\text { 2. Faktör } \\
\text { (Okul-çevre işbirliği) }\end{array}$ & 3,33 & ,79 &, $47^{* *}$ & 1 & & & & \\
\hline $\begin{array}{l}\text { 3. Faktör } \\
\text { (Değerlere dayalı } \\
\text { planlama) }\end{array}$ & 3,64 &, 81 &, $52^{* *}$ &, $60^{* *}$ & 1 & & & \\
\hline $\begin{array}{l}\text { 4. Faktör } \\
\text { (Öğretmen modelliği) }\end{array}$ & 3,98 & ,64 &, $61^{* *}$ &, $41^{* *}$ &, $50^{* * *}$ & 1 & & \\
\hline $\begin{array}{l}\text { 5. Faktör } \\
\text { (Okul yönetimi-öğretmen işbirliği) }\end{array}$ & 3,93 &, 73 &, $62^{* *}$ &, $58^{* *}$ &, $64^{* *}$ &, $63^{* *}$ & 1 & \\
\hline $\begin{array}{l}\text { 6. Faktör } \\
\text { (Personelin mesleki gelişimi) }\end{array}$ & 3,61 & ,67 &, $48^{* *}$ &, $54^{* * *}$ &, $39^{\text {*** }}$ &, $49^{* *}$ &, $45^{* *}$ & 1 \\
\hline$* * \mathrm{p}<.01$ & & & & & & & & \\
\hline
\end{tabular}

Tablo 3 'te faktörler arasındaki ilişkiyi belirlemek için yapılan korelasyon analizinden elde edilen sonuçların tamamında $p<.01$ düzeyinde anlamlı ilişki bulunmuştur. Faktörler arasında çok zayıf ya da çok güçlü ilişki bulunması ölçeğin iç tutarlılığına zarar verir. Bu sebeple faktörlerin orta düzeyde ilişkisinin olması beklenir (Akbulut, 2010). Elde edilen değerlerin hiçbirinde çok zayıf, yüksek ve çok yüksek ilişki bulunmamıştır.

\section{Doğrulayıcı Faktör Analizine İlişkin Bulgular}

Değer Merkezli Okul Kültürü Ölçeği’nin açımlayıcı faktör analizi sonucunda ulaşılan altı faktör altında toplanan 35 maddelik yapısının model-veri uyumunu değerlendirmek üzere 301 öğretmenden oluşan ikinci bir gruptan elde edilen veriler üzerinden doğrulayıcı faktör analizi uygulanmıştır. DFA'dan elde edilen uyum iyiliği değerleri kapsamında $\chi 2 /$ sd oranı, GFI, RMSEA, RMR, CFI ve IFI uyum indeksleri değerlendirilmiştir.

Doğrulayıcı faktör analizinde modelin uyum indekslerine yönelik analizler yapıldıktan sonra ölçek maddelerinin standartlaştırılmış regresyon katsayılarına bakılmış, düşük olduğu tespit edilen iki madde ölçekten çıkarılmış ve analiz tekrar yapıldığında uyum indekslerinde iyileşme olduğu görülmüştür. Ölçeğin 33 maddeden oluşan yapısına uygulanan DFA sonucu elde edilen bulgular değerlendirildiğinde Ki kare uyum testi olan $\chi^{2}$ /sd oran1 2.52 ( $\chi 2$ /sd=1204,949/477) 
bulunmuştur. Küçük örneklemlerde bu oranın $\leq 2.5$, büyük örneklemlerde ise $\leq$ 3 olmasının mükemmel uyum göstergesi olarak değerlendirilebileceği belirtilmektedir (Kline, 2005). Bununla birlikte 250 ve altı örneklem büyüklüğünde bu değerin $<2.5,250$ ve üzeri örneklem büyüklüğünde ise $<5$ olabileceğini belirten görüşler de bulunmaktadır (Byrne, 2011; akt: Yaşlıoğlu, 2017: 77). Bu araştırmada çalışma grubunun 301 kişiden oluştuğu dikkate alındığında mükemmel uyumu göstermektedir.

Oluşturulan modelin uyum iyiliği indeksi olan GFI, çalışma grubundaki kovaryans matrisinin model tarafindan ne düzeyde ölçüldüğünü ortaya koymaktadır. GFI değeri, çalışma grubunun büyüklüğünden etkilenmekte olup, çalı̧ma grubunda yer alan kişi sayısı arttıkça GFI değeri de artmaktadır. GFI değerinin 1 olmasının mükemmel uyum göstergesi olduğu belirtilmektedir (Jöreskog ve Sorbom, 1993). Bazı kaynaklarda ise model uyum değerlerinin .80 üzerinde çıkmasının da kabul edilebilir alt sınırlar olarak değerlendirileceği ifade edilmiştir (Cole, 1987; Gerbing ve Anderson, 1993). Bu araştırmada GFI= .80 olarak bulunmuş ve yeterli düzeyde olduğu kabul edilmiştir.

Karşılaştırmalı uyum indeksini ifade eden CFI değeri, 0 ile 1 arasında bir değer almakta ve bu değer 1'e yaklaştıkça uyum iyiliği derecesi de artmaktadır. Yüksek CFI değerine sahip bir modelin güçlü bir uyum sergilediği kabul edilmektedir. CFI değerinin $\geq 0,90$ olması kabul edilebilir, $\geq 0.95$ olması ise iyi uyum göstergesidir (Yılmaz ve Çelik, 2009; Şimşek, 2007). Bu çalışmada $\mathrm{CFI}=0.92$ bulunmuştur.

Yaklaşık ortalamaların karekökü olarak tanımlanan RMSEA, 0-1 arasında değer almaktadır. RMSEA değeri, 0.05 'in altında ise mükemmel uyum göstermekte, 0.08 'in altında ise kabul edilebilir uyum göstermektedir (Şimşek, 2007). $\mathrm{Bu}$ modelde RMSEA $=0.071$ olarak tespit edilmiştir. Kök artık kareler ortalamas1 olarak ifade edilen RMR değerinin, modelin iyi uyum göstermesi açısından 0 'a yaklaşması beklenmektedir. RMR değerinin $\leq 0.08$ olması iyi uyuma işaret etmektedir (Jöreskog ve Sorbom, 1993). Bu araştırmada ortaya konulan modelin RMR değeri 0.048 bulunmuş olup, iyi uyum gösterdiği anlaşılmaktadır.

Artan uyum indeksi olarak belirtilen IFI değeri, 0-1 arasında değer almakta ve 1'e yaklaştıkça mükemmel uyum gösterdiği belirtilmektedir. IFI değeri 0.90 üzerinde olduğunda kabul edilebilir uyum gösterdiği, 0.95 üzerinde ise mükemmel uyum sergilediği ifade edilmektedir (Jöreskog ve Sorbom, 1993). $\mathrm{Bu}$ çalışmada IFI $=0.92$ bulunmuştur. 
Doğrulayıcı faktör analizinde "Değerler eğitimini izleme ve değerlendirme" boyutunda yer alan "s29. Değerlerin öğretilmesi, okulumuzda öğrencilerin akademik başarılarına olumlu etki etmektedir." ve "s30. Okulumuzda değerlerin öğretilmesi, öğrencilerin okula olan aidiyetlerini ve devam durumlarını pozitif yönde etkilemektedir" maddeleri arasında; "Değerlere dayalı vizyon-stratejik planlama" boyutunda yer alan "s1. Okulumuzun değerler eğitimi konusundaki bakış açısı toplumun temel değerlerini yansıtmaktadır" ve "s2. Okulumuzda tüm paydaşlar (veli, öğretmen, öğrenci, STK, okul personeli vb.) tarafindan önemsenen değerlere dayalı ortak bir vizyon bulunmaktadır" maddeleri ile "s6. Okulda hangi değerlerin öğretileceği konusunda tüm paydaşların (veli, öğretmen, öğrenci, STK, okul personeli vb.) ortak bir anlayışı bulunmaktadır" ve "s7. Okulda öğretilecek değerlerin belirlenmesinde tüm paydaşların (veli, öğretmen, öğrenci, STK, okul personeli vb.) görüşleri alınmaktadır" maddeleri arasında toplamda üç modifikasyon yapılmıştır. Bu modifikasyonların modelin uyumuna anlamlı katkı sağladığı belirlenmiştir.

\section{Güvenirliğe İlişkin Bulgular}

Değer merkezli okul kültürü ölçeği'nin 33 maddeden oluşan yapısı için yapılan güvenirlik analizinde Cronbach Alpha değeri ,964 bulunmuştur. Literatürde bu değerin ,70 üzerinde çıkması ölçeğin iç tutarlılığa sahip olduğunu göstermektedir (Büyüköztürk, 2016). Ölçeğin son haline uygulanan güvenirlik analizi kapsamında ortaya çıkan madde analizi sonuçları Tablo 4'te yer almaktadır.

Tablo 4: Ölçeğin Geneline İlişkin Madde Analizi Sonuçları

\begin{tabular}{lllll}
\hline $\begin{array}{l}\text { Madde } \\
\text { No }\end{array}$ & $\begin{array}{l}\text { Madde Silindiğinde } \\
\text { Ölçek Ortalaması }\end{array}$ & $\begin{array}{l}\text { Madde Silindiğinde } \\
\text { Ölçek Varyansı }\end{array}$ & $\begin{array}{l}\text { Düzeltilmiş Madde- } \\
\text { Toplam Korelasyonu }\end{array}$ & $\begin{array}{l}\text { Madde Silindiğinde } \\
\text { Cronbach Alfa Değeri }\end{array}$ \\
\hline 1. & 120,206 & 409,464 &, 598 &, 963 \\
\hline 2. & 120,327 & 407,021 &, 703 &, 962 \\
\hline 3. & 120,272 & 409,069 &, 658 &, 963 \\
\hline 4. & 120,493 & 403,037 &, 744 &, 962 \\
\hline 5. & 120,648 & 402,938 &, 687 &, 962 \\
\hline 6. & 120,655 & 403,303 &, 719 &, 962 \\
\hline 7. & 120,808 & 402,728 &, 718 &, 962 \\
\hline 8. & 120,910 & 404,299 &, 647 &, 963 \\
\hline 9. & 120,583 & 405,012 &, 692 &, 962 \\
\hline 10. & 120,645 & 404,539 &, 671 &, 962 \\
\hline 11. & 120,755 & 404,529 &, 720 &, 963 \\
\hline 12. & 120,904 & 406,226 &, 645 &, 962 \\
\hline 13. & 120,790 & 403,195 &, 711 & \\
\hline
\end{tabular}




\begin{tabular}{lllll}
\hline 14. & 120,527 & 405,021 &, 736 &, 962 \\
\hline 15. & 120,436 & 407,219 &, 624 &, 963 \\
\hline 16. & 120,250 & 405,237 &, 754 &, 962 \\
\hline 17. & 120,390 & 403,647 &, 721 &, 962 \\
\hline 18. & 120,278 & 406,338 &, 718 &, 962 \\
\hline 19. & 120,446 & 403,188 &, 737 &, 962 \\
\hline 20. & 120,141 & 413,397 &, 580 &, 963 \\
\hline 21. & 120,066 & 414,766 &, 557 &, 963 \\
\hline 23. & 119,990 & 417,729 &, 479 &, 964 \\
\hline 25. & 120,337 & 412,696 &, 577 &, 963 \\
\hline 26. & 120,551 & 412,918 &, 517 &, 963 \\
\hline 27. & 120,660 & 407,759 &, 633 &, 963 \\
\hline 28. & 120,513 & 412,360 &, 549 &, 963 \\
\hline 29. & 120,210 & 413,445 &, 571 &, 963 \\
\hline 30. & 120,227 & 411,447 &, 635 &, 963 \\
\hline 31. & 120,377 & 408,137 &, 680 &, 962 \\
\hline 32. & 120,148 & 409,374 &, 641 &, 963 \\
\hline 33. & 120,162 & 410,247 &, 640 &, 963 \\
\hline 34. & 120,288 & 407,569 &, 704 &, 962 \\
\hline 35. & 120,162 & 409,861 &, 639 &, 963 \\
\hline
\end{tabular}

Güvenirlik kapsamında ayrıca ölçeğin her bir faktörü için ayrı ayrı analizler yapılmış ve birinci faktörden başlayarak Cronbach Alpha katsayıları sırasıyla; . 946; .915; .924; .807; .915 ve .842 olarak bulunmuştur. Tüm değerlerin .70'in üstünde olması ölçeğin iç tutarlılığının yüksek olduğunu göstermektedir. Maddelerin faktör içerisinde aldığı düzeltilmiş madde toplam korelasyonlarına bakıldığında birinci faktör .74 ile .86 arasında, ikinci faktör .68 ile .78 arasında, üçüncü faktör .68 ile .80 arasında, dördüncü faktör .55 ile .66 arasında, beşinci faktör .70 ile .82 ve altıncı faktör .68 ile .74 arasında değerler almıştır. Ayrıca faktörlerdeki her bir maddenin Cronbach Alpha değerinde bir artış oluşturmad1ğ1 görülmüştür. Analiz sonuçlarına göre faktörleri oluşturan her bir maddenin iç tutarlılığının yüksek olduğunu anlaşılmaktadır. Faktörler bazında madde analizi sonuçları Tablo-5'de verilmiştir. 
Tablo 5: Faktörler Bazında Madde Analizi Sonuçları

\begin{tabular}{|c|c|c|c|c|c|}
\hline Faktörler & $\begin{array}{l}\text { Madde } \\
\text { No }\end{array}$ & $\begin{array}{l}\text { Madde Silin- } \\
\text { diğinde Ölçek } \\
\text { Ortalaması }\end{array}$ & $\begin{array}{c}\text { Madde Silindiğinde } \\
\text { Ölçek Varyansı }\end{array}$ & $\begin{array}{l}\text { Düzeltilmiş } \\
\text { Madde-Toplam } \\
\text { Korelasyonu }\end{array}$ & $\begin{array}{l}\text { Madde } \\
\text { Silindiğinde } \\
\text { Cronbach Alfa } \\
\text { Değeri }\end{array}$ \\
\hline \multirow{7}{*}{$\begin{array}{l}\text { 1.Faktör: } \\
\text { Değerler } \\
\text { Eğitimini } \\
\text { İzleme ve } \\
\text { Değerlendirme }\end{array}$} & 29 & 23,790 & 21,134 & ,745 & ,944 \\
\hline & 30 & 23,807 & 20,799 & ,799 & ,940 \\
\hline & 31 & 23,958 & 20,246 & ,806 & ,939 \\
\hline & 32 & 23,728 & 19,812 &, 864 & ,934 \\
\hline & 33 & 23,742 & 20,031 &, 868 & ,934 \\
\hline & 34 & 23,869 & 20,146 &, 831 & ,937 \\
\hline & 35 & 23,742 & 20,176 &, 828 & ,937 \\
\hline \multicolumn{3}{|c|}{ Madde Sayısı: 7} & \multicolumn{3}{|c|}{ Cronbach Alfa Değeri: ,946 } \\
\hline \multirow{7}{*}{$\begin{array}{l}\text { 2. Faktör: } \\
\text { Okul-Çevre } \\
\text { İşbirliği }\end{array}$} & 8 & 20,950 & 23,300 &, 746 & ,901 \\
\hline & 9 & 20,623 & 23,839 & ,768 & ,899 \\
\hline & 10 & 20,685 & 23,888 & ,719 & ,904 \\
\hline & 11 & 20,795 & 23,894 & ,781 & ,897 \\
\hline & 12 & 20,944 & 23,950 &, 734 & ,902 \\
\hline & 13 & 20,830 & 23,783 &, 740 & ,902 \\
\hline & 14 & 20,567 & 24,939 &, 688 & ,907 \\
\hline \multicolumn{3}{|c|}{ Madde Sayısı: 7} & \multicolumn{3}{|c|}{ Cronbach Alfa Değeri: ,915 } \\
\hline \multirow{7}{*}{$\begin{array}{l}\text { 3. Faktör: } \\
\text { Değerlere } \\
\text { Dayalı } \\
\text { Vizyon- } \\
\text { Stratejik } \\
\text { Planlama }\end{array}$} & 1 & 21,951 & 24,345 & ,681 & ,919 \\
\hline & 2 & 22,072 & 24,027 & ,769 & ,911 \\
\hline & 3 & 22,018 & 24,413 &, 737 & ,914 \\
\hline & 4 & 22,238 & 23,101 &, 800 & ,908 \\
\hline & 5 & 22,393 & 22,469 &, 797 & ,908 \\
\hline & 6 & 22,400 & 23,025 &, 786 & ,909 \\
\hline & 7 & 22,553 & 23,084 &, 759 & ,912 \\
\hline \multicolumn{3}{|c|}{ Madde Sayısı: 7} & & \multicolumn{2}{|c|}{ Cronbach Alfa Değeri: ,924 } \\
\hline \multirow{4}{*}{$\begin{array}{l}\text { 4. Faktör: } \\
\text { Öğretmen } \\
\text { Modelliği }\end{array}$} & 20 & 12,184 & 3,817 & ,640 &, 750 \\
\hline & 21 & 12,108 & 3,847 & ,662 &, 740 \\
\hline & 23 & 12,033 & 3,973 &, 644 & ,749 \\
\hline & 25 & 12,380 & 3,942 &, 553 &, 794 \\
\hline \multicolumn{3}{|c|}{ Madde Sayısı: 4} & & \multicolumn{2}{|c|}{ Cronbach Alfa Değeri: , 807} \\
\hline \multirow{5}{*}{$\begin{array}{l}\text { 5. Faktör: } \\
\text { Okul } \\
\text { Yönetimi- } \\
\text { Öğretmen } \\
\text { İşbirliği }\end{array}$} & 15 & 15,405 & 11,243 & ,706 & ,912 \\
\hline & 16 & 15,219 & 11,204 &, 821 & ,889 \\
\hline & 17 & 15,359 & 10,634 &, 826 &, 887 \\
\hline & 18 & 15,247 & 11,491 &, 757 & ,901 \\
\hline & 19 & 15,415 & 10,737 &, 812 &, 890 \\
\hline \multicolumn{3}{|c|}{ Madde Sayısı: 5} & & \multicolumn{2}{|c|}{ Cronbach Alfa Değeri: ,915 } \\
\hline \multirow{3}{*}{$\begin{array}{l}\text { 6. Faktör: } \\
\text { Personelin } \\
\text { Mesleki } \\
\text { Gelişimi }\end{array}$} & 26 & 7,212 & 2,873 &, 689 & ,797 \\
\hline & 27 & 7,321 & 2,767 & ,689 & ,799 \\
\hline & 28 & 7,174 & 2,829 &, 744 &, 745 \\
\hline
\end{tabular}




\section{Sonuç}

Bu çalışmada, değer merkezli okul kültürünün belirlenebilmesi amacıyla bir ölçek geliştirilmesi amaçlanmıştır. Bu ölçeğin geliştirilmesi için öncelikle ilgili alan yazın taranmış ve 57 maddenin yer aldığı bir madde havuzu oluşturulmuştur. Ardından uzman görüşleri de alınarak beşli Likert tipinde 54 maddelik taslak form geliştirilmiş, iki farklı gruptan alınan verilerle geçerlik ve güvenirlik çalışmaları gerçekleştirilmiştir. Değer merkezli okul kültürünü belirlemek amacyyla hazırlanan bu 54 maddelik taslak form önce 247 öğretmene uygulanmış, madde analizleri yapıldıktan sonra korelasyon katsayısı .30'un altında kalan dört madde ölçekten çıkarılmıştır. Kalan 50 maddenin Cronbach Alfa güvenirlik katsayısı ise .970 olarak bulunmuştur.

Geçerlik çalışması kapsamında yapılan açımlayıcı faktör analizi sonucunda bazı maddelerin birden fazla faktörde yük göstermesi, bazı maddelerin ise içerik olarak ilişkili olmayan faktörlere dağılması nedeniyle 15 madde çıkarılarak ölçeğin toplam varyansının \% 69,56'sını açıklayan 35 madde ve 6 boyuttan oluşan bir ölçek elde edilmiştir. Ölçeğin toplam varyansının \% 69,56 olması, yap1 geçerliğinin iyi düzeyde olduğunu ve ilgili yapıyı iyi bir şekilde ölçtüğü anlamına gelmektedir. 35 maddelik ölçeğin Cronbach Alfa güvenirlik katsayıs1 .957 olarak bulunmuştur. Ölçekten elde edilen alt boyutlar ise sırasıyla değerler eğitimini izleme ve değerlendirme, okul çevre işbirliği, değerlere dayalı vizyon-stratejik planlama, öğretmen modelliği, okul yönetimi-öğretmen işbirliği ve personelin mesleki gelişimi olarak isimlendirilmiştir.

AFA sonucunda ulaşılan altı faktörlü modelin veriye uyumunu test etmek amaciyla 301 ögrretmenden oluşan ikinci bir gruptan toplanan verilerle doğrulayıcı faktör analizi gerçekleştirilmiştir. DFA'da modelin uyum indeksleri için yapılan analizde ölçek maddelerinin standartlaştırılmış regresyon katsayılarının incelenmesi sonucunda düşük değere sahip iki madde daha ölçekten çıkarılarak analiz tekrarlanmış ve uyum indekslerinde iyileşme tespit edilmiş̧ir. Ölçeğin kalan 33 maddelik yapısı üzerinden elde edilen DFA sonucunda altı faktörlü modelin kabul edilebilir düzeyde yapı geçerliği kriterlerini karşıladığı ve ölçeğin altı faktörlü yapısının doğrulandığı anlaşılmıştır.

Değer merkezli okul kültürü ölçeğinin güvenirliğini test etmek üzere hem ölçeğin bütünü hem de her bir alt boyutuna yönelik Cronbach's Alpha iç tutarlık katsayıları hesaplanmıştır. Ölçeğin genelinin Cronbach Alpha değeri ,964 bulunmuştur. Ölçeğin alt boyutları için hesaplanan iç tutarlılık katsayıları değerler 
eğitimini izleme ve değerlendirme için $\alpha=.946$; okul-çevre işbirliği için , $\alpha=$ .915; değerlere dayalı vizyon-stratejik planlama için $\alpha=.924$; öğretmen modelliği için $\alpha=.807$; okul yönetimi-öğretmen işbirliği için $\alpha=.915$; personelin mesleki gelişimi için $\alpha=.842$ olarak bulunmuştur. Elde edilen bu sonuçlar, ölçeğin iç tutarlılığının son derece yüksek ve güvenilir olduğunu göstermektedir.

Sonuç olarak, geliştirilen ölçek okulların değer merkezli bir okul kültürüne sahip olup olmadıklarının belirlenmesi ve ölçekteki boyutların dikkate alınmas1 suretiyle bunun oluşturulması süreçlerine katk1 sağlanması amaciyla öğretmenlere ve yöneticilere uygulanabilir. Ölçeğin geliştirilmesinde farklı okul türü, branş ve eğitim kademesi gibi değişkenler dikkate alınarak çalışma grubu oldukça geniş tutulmuştur. Ölçeğin belirli okul türleri veya belirli branşlar gibi farklı gruplarda kullanılması halinde bu gruplar için de geçerlik ve güvenirlik çalışmalarının yapılması düşünülebilir.

\section{Kaynakça}

Acat, M. B. ve Aslan, M. (2011). Okulların karakter eğitimi yetkinliği ölçeği (OKEYÖ). Değerler Eğitimi Dergisi, 9(21), 7-27.

Akbulut, Y. (2010). Sosyal bilimlerde SPSS uygulamaları. İstanbul: İdeal Kültür Yayınları.

Büyüköztürk, Ş. (2016). Sosyal bilimler için veri analizi el kitabl. Ankara: Pegem Akademi.

Byrne, B. M. (2011). Structural equation modeling with AMOS Basic concepts, Applications, and programming (multivariate applications series), Routledge, New York.

Cole, D. A. (1987). Utility of confirmatory factor analysis in test validation research. Journal of Consulting and Clinical Psychology, 55(4), 584-594.

Curriculum Corporation (2006). Implementing the national framework for values education in australian schools: report of the values education good practice schools project - stage I. Australia: Curriculum Corporation.

Curriculum Corporation (2008). At the heart of what we do: values education at the centre of schooling - the final report of the values education good practice schools project-stage 2. Australia: Curriculum Corporation.

Demircioğlu, İ. H. ve Tokdemir, M. A. (2008). Değerlerin oluşturulma sürecinde tarih eğitimi: amaç, işlev ve içerik. Değerler Eğitimi Dergisi, 6(15), 69-88.

Demirtaş, Z. ve Ekmekyapar, M. (2012). İlköğretim okulu yöneticilerinin değerlere dayalı yönetim uygulamalarının okul kültürüne etkisi. Kuram ve Uygulama- 
da Ë̆itim Yönetimi, 18(4), 523-544.

Ekşi, H., Türk, T. ve Avcu, A. (2017). Maryland güvenli ve destekleyici okul ilkimi ölçeği (mgdoi)'nın türk kültürüne uyarlanması: geçerlik ve güvenirlik çalışması. Abant İzzet Baysal Üniversitesi Eğitim Fakültesi Dergisi, 17(4), 1882-1899.

Firat, N. (2007). Okul kültürü ve ögrretmenlerin değer sistemleri. Doktora Tezi, Dokuz Eylül Üniversitesi Eğitim Bilimleri Enstitüsü, İzmir.

Gerbing D. W. ve Anderson J. C. (1993). Monte Carlo evaluations of the goodnessof-fit indices for structural equation models. K. A. Bollen Ve J. S. Long, (Ed.), Testing Structural Equation Models, (40-65). Newbury Park, CA: Sage.

Göldağ, B. (2015). Ortaögretim kurumlarında okul kültürü yoluyla değerler ĕgitimi (Malatya ili örneği). Doktora Tezi, İnönü Üniversitesi Eğitim Bilimleri Enstitüsü, Malatya.

Gruenert, S. W. and Valentine, J. (1998). School culture survey. Columbia, MO: Middle Level Leadership Center, University of Missouri.

Halstead, J. M. (2005). Values and values education in schools. (edt: J.M. Halstead \& M.J. Taylor) Values in Education and Education in Values, (2-13). UK: The Falmer Press.

Jöreskog, K. G. and Sörbom, D. (1993). LISREL 8: Structural equato in modeling with the simplis command language. Lincolnwood: Scientific Software Internaional, Inc.

Kalayc1, Ş. (2005). SPSS uygulamalı çok değişkenli istatistik teknikleri. Ankara: Asil Yayınevi.

Kantek, F., Baykal, Ü. ve Altundaş, S. (2010). Okul kültürü ölçeğinin geliştirilmesi. Anadolu Hemşirelik ve Sağllk Bilimleri Dergisi, 13(4), 36-43.

Karasar, N. (2016). Bilimsel araştırma yöntemi: kavramlar ilkeler teknikler. Ankara: Nobel Yayın Dağıtım.

Kaymakcan, R. ve Meydan, H. (2016). Ahlak değerler ve eğitimi. İstanbul: Dem Yayınları.

Kline, R. B. (2005). Principles and practice of structural equation modeling. NY: Guilford Publications, Inc.

Milson, A. J. ve Ekşi, H. (2003). Öğretmenlerin karakter eğitiminde yetkinlik duygusu konusunda bir ölçme aracına doğru: karakter eğitimi yetkinlik skalası (KEYİS) ve türkçeye uyarlanma çalışması. Değerler Eğitimi Dergisi, 1(4), 99-130.

Özdemir, A. (2006). Okul kültürünün oluşturulması ve çevreye tanıtılmasında okul müdürlerinden beklenen okul müdürlerinden beklenen ve onlarda gözlenen davranışlar. Türk Ĕgitim Bilimleri Dergisi, 4(4), 411-433. 
Özden, Y. (2005). Eğitimde yeni değerler. Ankara: Pegem A Yayıncılık.

Peterson, K. D. and Deal, T.E. (1990). The principal's role in shaping school culture. Research in brief. Washington, D.C: Department of Education, Office of Educational Research and Improvement.

Peterson, K. D. and Deal, T.E. (2002). The shaping school culture fieldbook. San Fransisco California USA: Jossey-Bass Inc. Publishers.

Şahin, S. (2010). Okul kültürünün bazı değişkenler açısından incelenmesi. İlkögretim Online, 9(2), 561-575.

Şahin Firat, N. (2010). Okul müdürü ve öğretmenlerin okul kültürü ile değer sistemlerine ilişkin algıları. Eğitim ve Bilim Dergisi, 35(156), 71-83.

Şencan, H. (2005). Sosyal ve davranışsal ölçümlerde güvenilirlik ve geçerlilik. Ankara: Seçkin Yayınları

Şimşek, Ö. F. (2007). Yapısal eşitlik modellemesine girişs temel ilkeler ve LISREL uygulamaları. Ankara: Ekinoks Yayınları.

Şimşek, Y. (2005). Okul müdürlerinin iletişim becerileri ile okul kültürü arasındaki ilişki. Eskişehir: Anadolu Üniversitesi Yayınları.

Tabachnick B. G., and Fidell, L. S. (2001). Using multivariate statistics. MA: Allyn \& Bacon.

Tavşancıl, E. (2006). Tutumların ölçülmesi ve SPSS ile veri analizi. Ankara: Nobel Yayın Dağıtım.

Terzi, A. R. (2005). İlköğretim okullarında örgüt kültürü. Kuram ve Uygulamada Ĕ̈itim Yönetimi Dergisi, 43, 423-442.

Uysal, E. (2008). Çağımızda değer kaymalarının doğurduğu sonuçlar ve etik kimliğin korunması. Uludağ Üniversitesi Illahiyat Fakültesi Dergisi, 17(1). 6779.

Yaşlıŏlu, M. M. (2017). Sosyal bilimlerde faktör analizi ve geçerlilik: keşfedici ve doğrulayıcı faktör analizlerinin kullanılması. Istanbul Üniversitesi İşletme Fakültesi Dergisi, 46, Özel Sayl, 74-85.

Yılmaz, V. ve Çelik, H. E. (2009). LISREL ile yapısal eşitlik modellemesi-I. Ankara: Pegem Akademi.

Zengin, M. (2017). Bir uygulama modeli olarak Avustralya'daki okullarda değerler eğitimi. Uluslararası Sosyal Araştırmalar Dergisi, 10(52), 866-883. 


\title{
Development of Values-Centered School Culture Scale:
} A study of Validity and Reliability

\author{
Mahmut ZENGiN, Corresponding Author. Assoc. Prof. \\ Sakarya University, Faculty of Theology, Department of Primary School Religion and Ethics Education \\ E-mail: zengin@sakarya.edu.tr \\ ORCID: 0000-0002-9042-7379
}

Muhammet Enes ÇELIK, M.D. Student.

Sakarya University, Institute of Educational Sciences.

E-mail: enescelik5419@gmail.com

ORCID: 0000-0001-8269-8681

\section{Introduction}

With specific significance to human existence, value/s can be defined as a concept that affect humans' thoughts and actions by setting general guidelines for directing individuals' behaviors (Uysal, 2008; Halstead, 2005; Demircioğlu ve Tokdemir, 2008), and it is a subject that has received much attention in multiple fields like; education, politics, business world, and media. Under the monopoly of the positivist understanding of science, schools did not take the necessary initiative to teach values. For this reason, in the educational circles, the schools' role and responsibilities in the teaching values, started to be expressed. Values education as a shared responsibility of teachers, students, parents, school management and all other stakeholders in the society, it is of critical importance that schools create a culture based on values (Zengin, 2017). 


\section{Values-Centered School Culture}

When we look at the definitions of school culture, we can see that one dimension, if any, related to values is taken into consideration. School culture is a structure that school administrators, teachers and all other stakeholders have created and developed, and this structure determines the behaviors, norms and values in the school with regulating the relationships between individuals. School culture determines the way the school is perceived by the inside/outside environment of the school and reflects the school's lifestyle (Göldağ, 2015: 78). Factors like; the age and history of the school, its aims and objectives, the socio-economic levels of the students, the socio-economic and geographical environment of the school, the physical and technological opportunities of the school, the expectations of the teachers and students, the expectations of parents, the structure of the education system, all contribute to the formation of school culture (Özdemir, 2006: 414-415).

In this study a definition of values-centered school culture is done through the notion that all stakeholders, from administrators to teachers, from school environment, institutions to students, all share the responsibility in the process of values acquisition whether explicitly or implicitly. In addition, the central position of the values and their relation with all dimensions that contribute to the formation of school culture are emphasized values that affect the formation of school culture. Although many dimensions can be mentioned in the formation of the values-centered school culture, we thought that it is important to consider the following dimensions that might shed light on the theoretical framework of the scale development process.

\section{Values-based vision and strategic planning:}

Vision is defined as a long-term process in which targets are sets forth to be reached in the future (Özden, 2005). Today, it is known that the goals and practices of the schools are very important for increasing the academic success of the students. However, schools do not show sufficient interest in teaching of values as much as enhancing academic achievement, thus they cannot provide an integrated study in this regard. Therefore, there is a need for a value-focused vision and planning that put forth by all stakeholders related to school education.

\section{Integrated Program:}

Values education should not be viewed as a separate part of any education program or a curriculum, but as a subject that integrated in all curricula as a whole. 
In this context, seeing values education as part of a certain branch area and the reluctance of other subject areas in taking initiative in this regard making the process of values acquisition very difficult. Therefore, values education should be seen as a complementary and integral component in all curricula (Curriculum Corporation, 2008).

\section{Modeling:}

The process of modelling - which can be defined as the reflections of the implicit or explicit expressions and behaviors of an individual in others' opinions, attitude and behavior - is considered as an integral component of successful values education practices. In addition to teachers being a role model in terms of transmitting values, it is also critical to cooperate with other stakeholders, especially the family, and to ensure their active participation in the process of values acquisition (Kaymakcan and Meydan, 2016).

\section{Professional Development for Staff:}

It is necessary to create values learning opportunities for administrative and teaching staff in the school and they should be carried out in a sustainable way.

\section{Collaboration with School Stakeholders:}

Creating values-centered school culture is not just the responsibility of the teaching staff. At the same time, it is necessary to involve all the environmental factors like the school staff, family, local and civil society elements in all their dimensions and enhance their collaboration. Although involving many people in an initiative about values education might take much time and labor but on the other hand it provides a more robust compromise, consistency and sustainability (Curriculum Corporation, 2006).

\section{Relevance to School and Society:}

Taking into account the society and the school in which the value acquisition takes place, means taking into account the needs of a specific society with its historical and cultural values, taking into account the manner in which these values are understood and the behavioral standards created by those values, and finally it means taking into account the values reflected in the relations between individuals. 


\section{The Research Purpose}

The aim of this study is to determine the evaluation of values-centered school by teachers by developing a valid and reliable scale to measure this. When all dimensions of the values-centered school culture scale are taken into consideration, studies in the literature on the planning and development of the values education of schools, with the critical functions of the teachers can be found, yet in this study, the dimensions that affecting the school culture with their relationship with values are discussed in a more specific and inclusive manner. For this reason, in each dimension of the school culture in the scale items that highlight the effects and functions of values are included, and the relationship between school culture and values is aimed to be constructed in a clear way. The feedback to be obtained with this scale in terms of assessing on which level were values taken into account in creating school culture that they or in the one that was created.

\section{Method}

In the development of the values-centered school culture scale, descriptive survey model as a qualitative approach is used to reflect the current cases or the ones that have passed (Karasar, 2016).

\section{Working Group}

In the process of development of Values-Centered School Culture Scale, 247 teachers working in Sakarya were included in the study, and 301 teachers participated for Exploratory Factor Analysis (EFA), in total 548 teachers contributed to the study. Two different study groups were assigned for both (EFA) and (CFA).

\section{Data Collection Tool}

In the process of preparation of the scale, firstly, a 57 item pool was created based on a review of the relevant literature. In order to check the content validity of these items, four academicians and a linguist examined these items and then necessary corrections were made. Furthermore, in order to measure the intelligibility of these items, think-aloud technique used by four teachers by answering the items out laud. During this process, items which found difficult to 
understand by teachers and the ones entailed indecision identified by researchers. As a result of all these procedures that involved academicians and linguists 3 items that found difficult to understand by teachers were discarded from the scale, thus a 54-item structure was reached. After EFA and CFA were applied to the scale, a final scale of 33-item and 6 sub-dimensions was reached.

\section{Data Analysis}

After the examination of Content validity, exploratory and confirmatory factor analysis were used to test the construct validity of the scale, and to test reliability Cronbach's Alpha internal consistency coefficient was calculated. Loss data analysis was performed for the obtained data and it was decided to perform the analysis by taking serial averages instead of the missing data. SPSS 22 and AMOS 21 programs were used for validity and reliability analysis.

\section{Results}

\section{Findings Related to Item Analysis}

Within the scope of the values-centered school culture scale, a 54-item draft $\mathrm{f}$ form was applied to 247 teachers. Corrected item total correlations were calculated in order to determine the predictive validity of the total score. In the evaluation of the item total correlation, items with .30 and above were considered to be sufficient to distinguish the quality to be measured (Büyüköztürk, 2016: 181) considering this 4 items were excluded from the scale. Corrected item-total correlations for the remaining 50 items were between .40 and .752 , and the Cronbach Alpha reliability coefficient was .970.

\section{Findings Related to Exploratory Factor Analysis}

Kaiser-Meyer Olkin (KMO) and Barlett Sphericity Test were applied to judge the suitability of the scale of 50 items to factor analysis. KMO value was calculated as .94 and Barlett Sphericity Test was found to be $(\chi 2=9841,43 ; p<.001)$ of significance. According to these results, it was seen that the data set was suitable for factor analysis.

In the exploratory factor analysis, deciding whether to discard the items .40 was determined as the lower limit of the factor load value. The load value of an 
item at different factors is determined to be at least .10. In this context, items correlating with multiple factors were excluded from the scale. Although there is a widespread acceptance in literature that the factor load value of an item should be at least .30 and above (Büyüköztürk, 2016; Tabachnick and Fidell, 2001), there are also who claim that it should be .40 (Şencan, 2005). As a result of the analysis, a structure consisting of 35 items and 6 sub-dimensions was reached. The sub-dimensions were named as follows; monitoring and evaluation of values education, school-environment cooperation, values-based vision-strategic planning, teacher modeling, school management-teacher cooperation and professional development for staff. The total variance explained by the six factors of the "Values-Centered School Culture Scale" was found to be $69.56 \%$. In order to analyze the internal consistency of the scale, the correlation values of the total scores of the scale were examined. When the correlation values between the factors were examined, it was seen that there was a moderate relationship.

\section{Findings Related to Confirmatory Factor Analysis}

In order to test the compliance of the data with the the six-factor model obtained from CFA, a confirmatory factor analysis was performed with data collected from a second group of 301 teachers. Within the scope of the goodness of fit values obtained from CFA, $(\chi 2 / \mathrm{sd})$ ratio, GFI, RMSEA, RMR, CFI and IFI were evaluated within the scope of compliance indices. The analysis done for the model fit indices in CFA, as a result of the examination of the standardized regression coefficients of the scale items, two items of low value were removed from the scale, and when the analysis was repeated improvement in fit index has been identified. When the findings of the CFA application to the remaining 33 items were evaluated, the Chi-Square goodness of fit test $\chi 2$ /sd ratio 2.52 $(\chi 2 / \mathrm{sd}=1204,949 / 477) ; \mathrm{GFI}=.80 ; \mathrm{CF}=.92 ; \mathrm{RMSEA}=.071 ; \mathrm{RMR} .048$ and IFI $=0.92$ were found. As a result of the CFA obtained from the 33-item structure of the scale, it was understood that the six-factor model met the criteria for construct validity at an acceptable level and the six-factor structure of the scale was confirmed.

\section{Findings Related to Reliability}

In order to test the reliability of the values-centered school culture scale Cronbach's Alpha internal consistency coefficients were calculated for each scale 
and for each sub-dimension. The general Cronbach's Alpha value for the scale was found to be 964 . The internal consistency coefficients calculated for the sub-dimensions of the scale were: $\alpha=.946$ for monitoring and evaluating values education, $\alpha=.915$ for school-environment cooperation, $\alpha=.924$ for values-based vision-strategic planning, $\alpha=.807$ for teacher modeling; $\alpha=.915$ for school management-teacher collaboration, $\alpha=.842$ for the professional development of the staff. These results show that the internal consistency of the scale is extremely high and reliable.

\section{Conclusion}

This study was aimed to develop a scale in order to determine the values-centered school culture. As a result of analysis, a scale consisting of 6 dimensions and 33 items was obtained. The developed scale can be used to determine whether or not schools have values-centered school culture and by taking into account the dimensions in the scale it can contribute to the process of forming them by applying them to teachers and administrators. In the development of the scale, the working group was kept quite wide considering the variables such as different school types, branches and education levels. In case this scale is used on different groups such as; certain types of schools or specific branches, then validity and reliability examinations might conceivably be made for these groups. 